\title{
Hydride reorientation in Zircaloy-4 cladding
}

\author{
H.C. Chu ${ }^{a, b, *}$, S.K. Wu ${ }^{\text {a }}$, R.C. Kuo ${ }^{b}$ \\ a Department of Materials Science and Engineering, National Taiwan University, Taipei 10617, Taiwan, ROC \\ ${ }^{\mathrm{b}}$ Institute of Nuclear Energy Research, P.O. Box 3-14, Longtan, Taoyuan 32546, Taiwan, ROC
}

Received 2 December 2006; accepted 19 June 2007

\begin{abstract}
The formation of radial hydrides in stress-relief annealed Zircaloy-4 cladding was studied. Specimens were firstly hydrided to different target hydrogen levels from 100 to $600 \mathrm{wt}$ ppm and then thermally cycled in an autoclave under a constant hoop stress to form radial hydrides by a hydride reorientation process. The effect of thermal cycling on the hydride reorientation was more significant than that of isothermal treatment. Based on the experimental data, a thermodynamic model was proposed to elucidate the stress reorientation behavior of hydrides in Zircaloy cladding. According to the model, the bounds of stress and temperature to stress reorientation of hydride precipitates were developed. The threshold stress for hydrides to reorientation was a function of solution temperature and specimen hydrogen concentration.
\end{abstract}

(C) 2007 Elsevier B.V. All rights reserved.

PACS: $28.52 . \mathrm{Fa}$

\section{Introduction}

The mechanical properties of Zircaloy fuel cladding can be adversely affected by the presence of hydrides, especially when they are oriented towards the radial direction of the tubing (i.e. radial hydride) [1-4]. The formation of radial hydrides in Zircaloy materials is closely related to the fabrication history, texture and stress [5-8]. In order to retain sufficient ductility to keep its integrity during reactor service, Zircaloy fuel cladding tube is manufactured under well controlled condition to ensure that only circumferential hydride platelets are to develop during reactor service. However, radial hydrides can be formed, by a reorientation process, when a specimen is cooled down under stress from temperatures at which hydrides are dissolved. As is often the case, Zircaloy fuel cladding tends to be subjected to larger internal pressure and to have higher hydrogen content

\footnotetext{
* Corresponding author. Address: Institute of Nuclear Energy Research, P.O. Box 3-14, Longtan, Taoyuan 32546, Taiwan, ROC. Tel.: +886 3 4711400x6694; fax: +88634711409 .

E-mail address: hcchu@iner.gov.tw (H.C. Chu).
}

as its burnup increases. The higher hoop stress will make these hydrides more susceptible to stress reorientation when fuel cladding undergoes a temperature variation during reactor operation or under dry storage conditions [9-12]. Therefore, the factors determining the preferential orientation of hydride precipitates and the effects of radial hydrides on the integrity of cladding materials have been examined extensively.

The occurrence of hydride reorientation in Zircaloy fuel cladding usually involves the dissolution of circumferential hydrides and the formation of radial hydrides. Of the two processes, precipitation dominates the hydride reorientation process mechanistically. Hydride precipitation is a complicated function of the solubility of hydrogen in cladding materials, cladding hydrogen concentration, stress state, temperature, cooling rate and thermal cycling. So when characterizing the stress reorientation behavior of hydride precipitates in cladding materials, it is necessary to take into account these factors separately and synergistically. In this work, specimens of hydrogen levels between 130 and $600 \mathrm{wt} \mathrm{ppm}$ were thermal-cycled under a constant hoop stress to form radial hydrides. The dependence of the 
stress reorientation on the hydrogen concentration, thermal cycle number and solution temperature was investigated experimentally. A thermodynamic model for evaluating the susceptibility to radial hydride formation in the stress-relief annealed (SRA) Zircaloy-4 cladding was proposed and verified with the experimental results. With the model, the bounds of stress and temperature to stress reorientation of hydride precipitates were developed.

\section{Experimental}

\subsection{Material and hydriding process}

Stress-relief annealed (SRA) Zircaloy-4 cladding with an outside diameter of $9.5 \mathrm{~mm}$ and wall thickness of $0.58 \mathrm{~mm}$ was used. Its chemical composition is given in Table 1. Cladding tube, cut into $13 \mathrm{~cm}$ lengths, was first uniformly hydrogen-charged by a thermal cycling process. The specimen was encapsulated with a pre-determined amount of pure hydrogen in a Pyrex capsule of sufficient volume such that a low hydrogen partial pressure could be obtained to avert the formation of hydride layers. The encapsulated cladding specimen was then thermally cycled between $\sim 200^{\circ} \mathrm{C}$ and $300{ }^{\circ} \mathrm{C}$ for a certain number of cycles, depending on the target hydrogen concentration level. The heating and cooling rates were at $3{ }^{\circ} \mathrm{C} / \mathrm{min}$ and $2{ }^{\circ} \mathrm{C} / \mathrm{min}$, respectively [13]. The target hydrogen levels ranged from 100 to $600 \mathrm{wt}$ ppm. Hydrogen concentrations of Zircaloy-4 cladding specimens were determined by an inert-gas fusion method using a LECO RH-404 hydrogen determinator. Typically, hydrides were oriented in the circumferential direction and homogeneously distributed across the cross-section of the cladding specimen.

\subsection{Hydride reorientation experiment}

In order to obtain radial hydrides, the as-hydrided specimen was further subjected to thermal cycling in an autoclave under a constant hoop stress by regulating the differential pressure between its internal and external pressures with a constant differential pressure control system [13]. The tube was heated to $400{ }^{\circ} \mathrm{C}$ under a constant differential pressure of $20.7 \mathrm{MPa}$ that was equivalent to a hoop stress of $160 \mathrm{MPa}$ being applied on the tubing wall. After solution-annealed at $400{ }^{\circ} \mathrm{C}$ for $2 \mathrm{~h}$, the specimen was slowly cooled down at a cooling rate of $1{ }^{\circ} \mathrm{C} / \mathrm{min}$ to $170{ }^{\circ} \mathrm{C}$ to make up one thermal cycle. The experimental parameters of solution temperature and cooling rate were chosen to simulate dry storage conditions as close as possible. In this work, cladding tubes were treated under the same thermal and pressure conditions but different cycling

Table 1

Chemical compositions of Zircaloy-4 cladding tube ( $\left.\mathrm{wt}^{\mathrm{O}} \%\right)$

\begin{tabular}{llllllll}
\hline $\mathrm{Sn}$ & $\mathrm{Fe}$ & $\mathrm{Cr}$ & $\mathrm{O}$ & $\mathrm{N}$ & $\mathrm{C}$ & $\mathrm{H}$ & $\mathrm{Zr}$ \\
\hline 1.26 & 0.22 & 0.12 & 0.13 & 0.0029 & 0.01 & 0.0007 & Balance \\
\hline
\end{tabular}

numbers, i.e. 1, 2, 4, 8 and 12 cycles, to obtain specimens with various fractions of radial hydride precipitates. The reorientation experiment run was conducted in duplication for each of combination conditions of hydrogen concentration and cycle number. Besides, to study the effect of solution temperature on the hydride reorientation behavior, some specimens were solution annealed at the temperature $300{ }^{\circ} \mathrm{C}$ or $450{ }^{\circ} \mathrm{C}$ for $2 \mathrm{~h}$ and then cooled down to $170{ }^{\circ} \mathrm{C}$ at a rate of $1^{\circ} \mathrm{C} / \mathrm{min}$. Afterwards, the specimens were further furnace-cooled to room temperature, not thermally cycled.

\subsection{Analysis of hydride orientation}

Because the majority of hydride traces observed was either along the specimen hoop direction or perpendicular to it, hydride stringers were classified into two groups: circumferential and radial hydrides. The former was defined as the clusters with their precipitate planes oriented
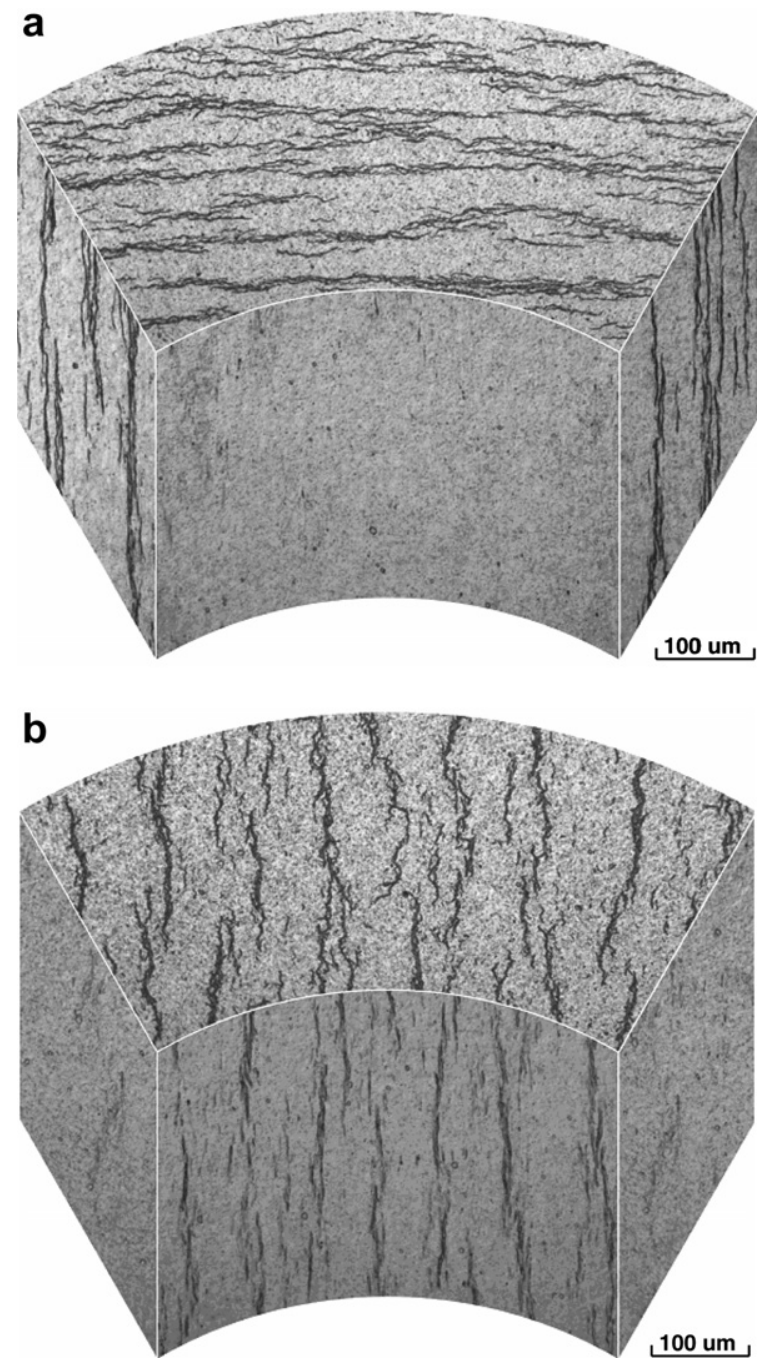

Fig. 1. Micrograph showing orientation of hydrides in Zircaloy-4 cladding of $\sim 230 \mathrm{ppm}$ : (a) as-hydrided and (b) after 8 cycles of thermal treatment. 
within $0-40^{\circ}$ to the reference (circumferential) axis; the clusters within $50-90^{\circ}$ to the reference axis were recognized as radial hydrides. The small clusters within $40-50^{\circ}$ to the reference axis were classified into neither of the two groups, and not counted into the total amount of hydrides. The percentage of radial hydrides was determined by calculating the areal fraction of radial strings on a photomicrograph. To provide a high-resolution digital image for this analysis, a digital camera with a CCD array of $2048 \times$ 2048 pixels was mounted on a microscope to project the hydride traces onto a screen. A magnification of 200 was selected. The orientation of hydride trace was recorded as each pixel in the image was scanned, the fraction of total pixels of hydrides in each category was then determined.

\section{Results}

\subsection{Effect of thermal cycling}

An example of reorientation of hydride precipitates in Zircaloy fuel cladding is given in Fig. 1. Most hydrides were circumferentially aligned and uniformly distributed across the as-hydrided cladding wall. The majority of the hydride traces was thick and long; there existed a minor amount of fine hydrides. In general, both the coarse and fine hydrides had the same orientation. With increasing the thermal cycle number, the reorientation of hydrides from the circumferential to radial direction became more noticeable. Fig. 2 shows the optical micrographs of hydrided cladding
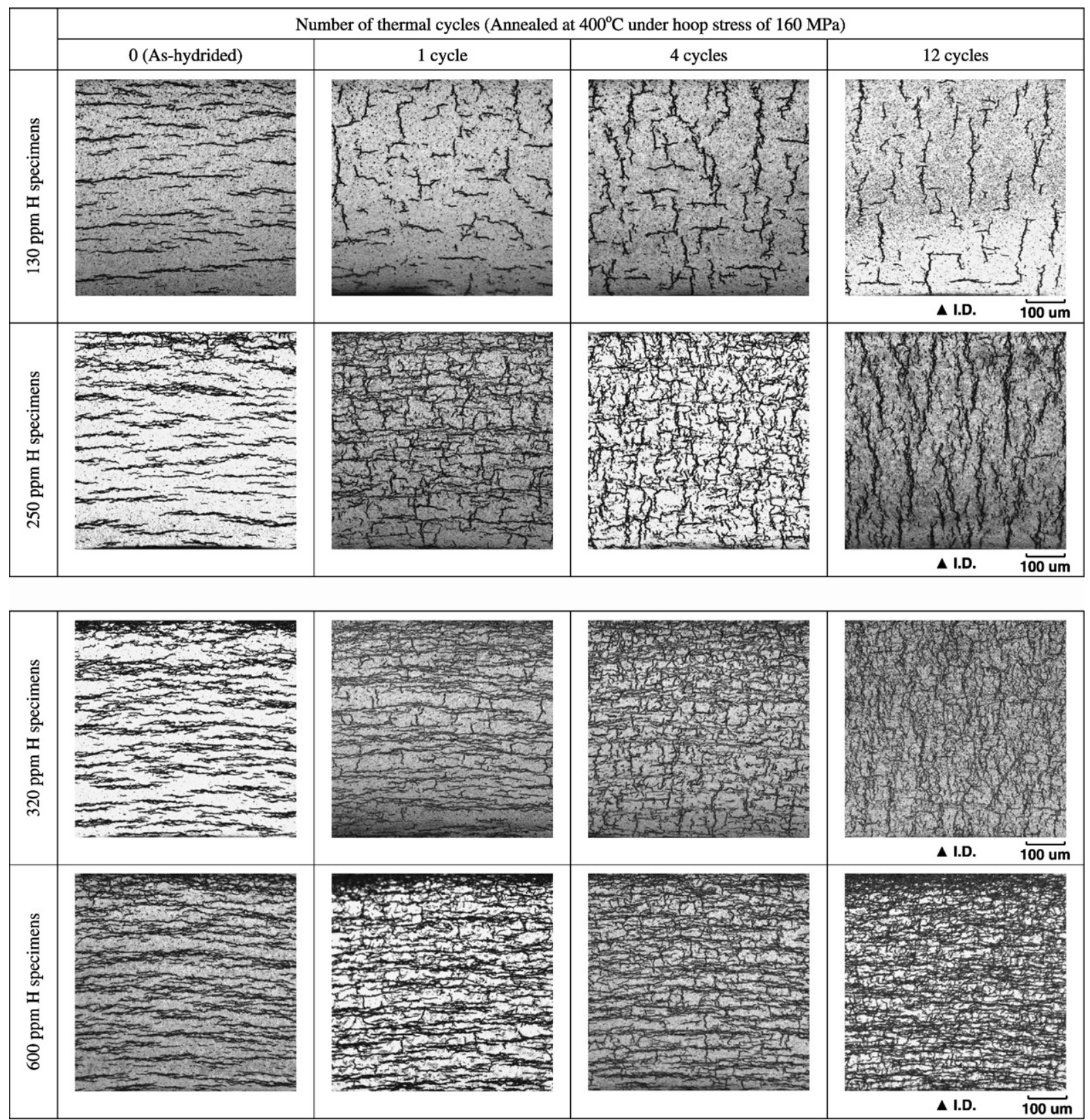

Fig. 2. Micrographs showing reorientation of hydrides in Zircaloy-4 cladding specimens subjected to thermal treatment to various cycle numbers. 


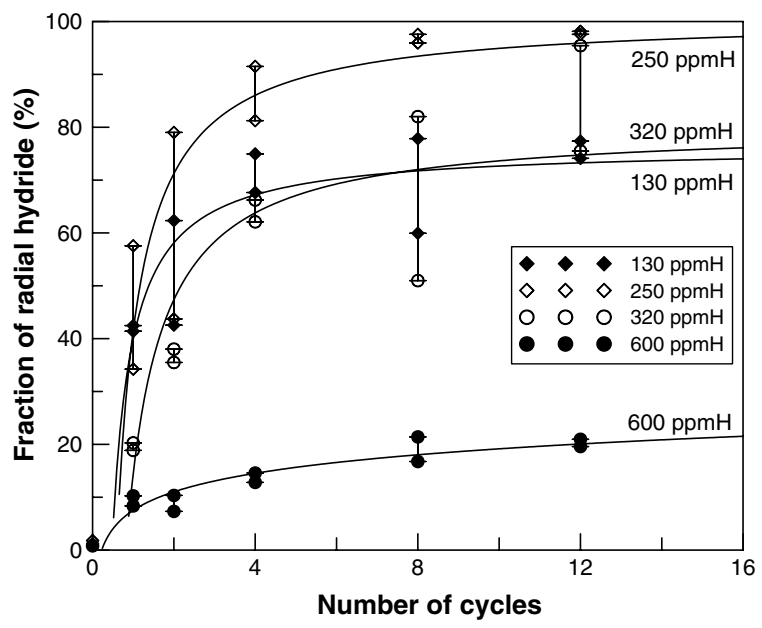

Fig. 3. Effect of the thermal cycle number on the hydride reorientation of cladding tubes with various hydrogen concentrations under the condition of solution temperature $400^{\circ} \mathrm{C}$ and hoop stress $160 \mathrm{MPa}$.

specimens heat-treated to different thermal cycle numbers. The dependence of hydride reorientation on the thermal cycle number and the hydrogen concentration is depicted in Fig. 3. The percentage of radial hydrides increased as the number of thermal cycles increased, until it reached a saturated value. After 12 cycles of thermal treatment, more than $90 \%$ of hydride precipitates in the $250 \mathrm{ppm} \mathrm{H}$ specimens were reoriented into radial hydrides. However, for the specimens with a lower hydrogen content of $130 \mathrm{ppm}$ or with a higher hydrogen content of $600 \mathrm{ppm}$, the applied stress of $160 \mathrm{MPa}$ induced a maximum of about $75 \%$ and $20 \%$ radial hydrides, respectively. According to the solubility data [14], zirconium and its alloy have a terminal solid solubility (TSS) of about $200 \mathrm{ppm}$ hydrogen at $400{ }^{\circ} \mathrm{C}$. For the $320 \mathrm{ppm} \mathrm{H}$ specimens solution-annealed at $400{ }^{\circ} \mathrm{C}$, there were about $120 \mathrm{ppm}$ hydrogen left in the form of hydride precipitate, not dissolved. However, a nearly complete reorientation of hydrides in one of the $320 \mathrm{ppm}$ $\mathrm{H}$ specimens was observed after 12 cycles of thermal treatment. Results obtained in this work imply that, under a combination of solution temperature $400{ }^{\circ} \mathrm{C}$ and hoop stress $160 \mathrm{MPa}$, a complete reorientation of all hydrides is possible for a $\sim 300 \mathrm{ppm} \mathrm{H}$ cladding specimen with the aid of repeated heating and cooling even though hydrides are not fully dissolved in each thermal cycle.

\subsection{Effect of specimen hydrogen content}

The lower curve in Fig. 4 shows the dependence of the stress reorientation on hydrogen concentration for the specimens subjected to one thermal cycle between $400{ }^{\circ} \mathrm{C}$ and $170^{\circ} \mathrm{C}$. The specimens of lower hydrogen contents were more susceptible to the stress reorientation than those higher ones. After 12 thermal cycles, the maximum amounts of radial hydrides obtained for specimens of different hydrogen contents are demonstrated by the upper curve in Fig. 4. A complete stress reorientation was

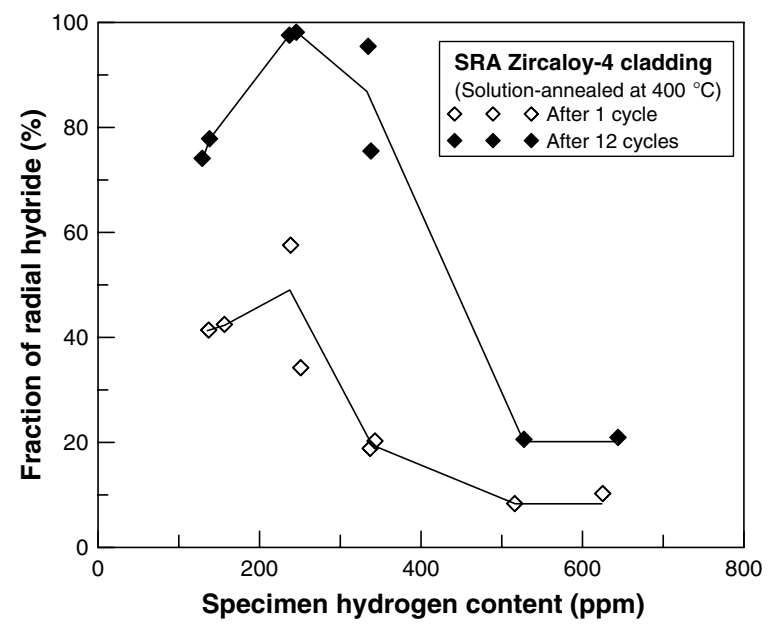

Fig. 4. The dependence of the stress reorientation on the hydrogen concentration (solution-annealing temperature is $400^{\circ} \mathrm{C}$ ).

obtained among the 250 and $320 \mathrm{ppm} \mathrm{H}$ specimens, but the $130 \mathrm{ppm} \mathrm{H}$ specimen gave a lower plateau value of approximately $75 \%$ radial hydrides. An increase in hydrogen concentration was to force nucleation at unfavorable sites or to raise the portion of un-dissolved hydrides which did not participate in the formation of radial hydrides, and thus the maximum amount of radial hydrides was inversely proportional to hydrogen concentration $[7,15]$. If the hydrogen concentration of a specimen is low enough, the temperature at which hydrides begin to nucleate from the saturated matrix should be taken into consideration when evaluating the formation of radial hydrides. So in the case of the $130 \mathrm{ppm} \mathrm{H}$ specimens, precipitation of hydrides did not occur until it was cooled down to below $350{ }^{\circ} \mathrm{C}$. But in the other case of the specimens of higher than $200 \mathrm{ppm}$, precipitation started once they were slowly cooled from the holding temperature of $400{ }^{\circ} \mathrm{C}$. The diffusion rates of hydrogen atom were relatively smaller at lower temperatures and the effect of stress on the hydride reorientation was less significant. Consequently, a smaller fraction of radial hydrides was obtained with the cladding specimens of lower bulk hydrogen concentrations.

\section{Modeling and discussion}

\subsection{Heterogeneous nucleation}

Nucleation in solids is almost always heterogeneous. Non-equilibrium defects such as excess vacancies, dislocations, grain boundaries and free surfaces increase the free energy of the material, which are the preferable sites for nucleation. The creation of a nucleus results in the destruction of a defect, some free energy $\left(\Delta G_{\mathrm{d}}\right)$ will be released, thereby reducing the activation energy barrier for nucleation. The free energy change associated with heterogeneous nucleation process can be expressed as below [16]:

$\Delta G_{\mathrm{Het}}=-V\left(\Delta G_{\mathrm{V}}-\Delta G_{\mathrm{S}}\right)+A \gamma-\Delta G_{\mathrm{d}}$, 
where $V$ is the volume of the solid precipitate, $A$ is the precipitate/matrix interfacial area, $\Delta G_{\mathrm{V}}$ is the free energy reduction per unit volume caused by the creation of precipitate and $\Delta G_{\mathrm{S}}$ is the misfit strain energy per unit volume of hydride.

The formation of radial hydrides is highly dependent on the hoop stress in the cladding. Zircaloy fuel cladding is processed with a large amount of compressive strain along the radial direction in the latter stages of manufacture to ensure that only circumferential hydrides are to be formed during reactor operation. The residual stress left after coldworking or an external stress is to favor the formation of particular stacks of hydrides having common orientation [17]. When cladding specimens are cooled down from solution temperatures under a tensile stress, some hydrides will precipitate out preferentially at those locations where maximum strain energy can be relieved. For this reason, the degree of stress reorientation here is assumed to be simply related to the energy preference among those heterogeneous sites, neglecting defects such as grain boundary, dislocation, etc. Ells [18] and Puls [19] have calculated the effect of an external stress on the orientation of hydrides. The preferential precipitation of hydrides under stress was the most determinant during the nucleation stage and was also proved experimentally by Hardie and Shanahan [15]. According to a thermodynamic model by Puls [19], the critical nucleation energy under an external stress $\sigma$ can be written as

$\Delta G_{\mathrm{Het}, \sigma}^{*}=\Delta G_{\mathrm{Het}, 0}^{*}+v_{0}^{*}\left(\Delta G_{\mathrm{i}}-\left(\frac{x}{\bar{v}_{\mathrm{hyd}}}\right) P \bar{v}_{\mathrm{H}}\right)$,

where $\Delta G_{\mathrm{Het}, 0}^{*}$ is the critical nucleation energy under zero external stress, $\Delta G_{\mathrm{i}}$ is the interaction energy per unit volume of hydride precipitation accompanied by the applied stress, $x$ is the hydride composition index for $\mathrm{ZrH}_{x}, v_{0}^{*}$ is the critical nucleus volume, $\bar{v}_{\text {hyd }}$ is the molar volume of $\delta$-hydride of composition $\mathrm{ZrH}_{x}, \bar{v}_{\mathrm{H}}$ is the molar volume of hydrogen in zirconium, and $P$ is the hydrostatic stress. If each nucleus can be made supercritical at a rate of $f$ per second, the heterogeneous nucleation rate will be given by an expression [16]:

$N_{\text {Het }}=f \cdot C^{*}$.

In Eq. (3), $f$ depends on how frequently a critical nucleus can receive an atom from the matrix and can be written as $\omega \exp \left(-\Delta G_{\mathrm{m}} / k T\right)$, where $\Delta G_{\mathrm{m}}$ is the activation energy for atomic migration, $\omega$ is a factor that includes the vibration frequency of the atoms and the area of the critical nucleus, $k$ and $T$ have their usual meanings. $C^{*}$ is the concentration of a critical-sized nucleus and can be expressed as $C^{*}=C_{1} \exp \left(\frac{-\Delta G_{\mathrm{Het}}^{*}}{k T}\right)$, where $C_{1}$ is the number of atoms per unit volume. Therefore, the nucleation rate will be rewritten in the form

$N_{\mathrm{Het}}=\omega C_{1} \exp \left(-\frac{\Delta G_{\mathrm{m}}}{k T}\right) \cdot \exp \left(-\frac{\Delta G_{\mathrm{Het}}^{*}}{k T}\right)$.
The majority of hydride traces observed is either along the specimen hoop direction or perpendicular to it. So these hydrides are classified into two groups of circumferential and radial hydrides and the ratio of radial hydrides can be calculated as

$n=\frac{N_{\text {rad }}}{N_{\text {rad }}+N_{\text {cir }}}$

and

$n^{-1}=\frac{N_{\text {rad }}+N_{\text {cir }}}{N_{\text {rad }}}=1+\frac{N_{\text {cir }}}{N_{\text {rad }}}$.

According to the optical metallographic examinations of the stress-free SRA cladding specimens of hydrogen levels between 130 and $600 \mathrm{wt} \mathrm{ppm}, n$ are less than $2 \%$ for all the as-hydrided specimens. Therefore, $49 C_{\mathrm{rad}}=C_{\mathrm{cir}}$ is assumed and we obtain

$n^{-1}=1+49 \cdot \exp \left(\frac{\Delta G_{\mathrm{rad}}^{*}-\Delta G_{\mathrm{cir}}^{*}}{k T}\right)$.

Substituting the critical nucleation energy $\Delta G^{*}$ from Eq. (2) into Eq. (7) gives

$n=\frac{1}{1+49 \cdot \exp \left\{\frac{v_{0}^{*}\left(\Delta G_{\mathrm{i}, \text { rad }}-\Delta G_{\mathrm{i}, \mathrm{iri}}\right)}{k T}\right\}}$.

With an applied hoop stress, the difference of the interaction energy between radial and circumferential hydrides is $-\sigma \cdot B$, where $\sigma$ is the applied hoop stress (positive when tensile) and $B$ is a constant. Then the percentage of radial hydrides can be rewritten as

$n=\frac{1}{1+49 \cdot \exp \left(-\frac{B v_{0}^{*} \sigma}{k T}\right)}$.

At a particular temperature, the proportion of radial hydride platelets increases with the applied hoop stress. The critical volume of a nucleus $\left(v_{0}^{*}\right)$ is proportional to $\left(\Delta G_{\mathrm{V}}-\Delta G_{\mathrm{S}}\right)^{-3}$ that can be obtained by differentiating Eq. (1). For a dilute solution, the volume free energy change is proportional to the magnitude of undercooling $(\Delta T)$ [16], the critical volume therefore can be expressed as $v_{0}^{*}=\frac{B^{\prime}}{(\Delta T)^{3}}$ if $\Delta G_{\mathrm{V}} \gg \Delta G_{\mathrm{S}}$ and Eq. (9) is further simplified as

$n=\frac{1}{1+49 \cdot \exp \left(-\frac{D \sigma}{(\Delta T)^{3} T}\right)}$,

where $D$ is a constant.

\subsection{Applications}

\subsubsection{Effects of stress, temperature and hydrogen concentration on the stress reorientation}

Eq. (10) shows that a large undercooling or small hoop stress would tend to reduce the orienting efficiency of the nucleation stage. On the basis of terminal solid solubility data $[20,21]$, it is possible to calculate the undercooling 
required to initiate nucleation [19]. In this study, all specimens were heat treated under the same cooling rate, so the formation of radial hydrides can be merely expressed as a function of stress and solution temperature. Eq. (10) is capable of predicting the stress reorientation behavior of hydride precipitates in cladding materials under different combinations of temperature and hoop stress. Instead of considering complex parameters that vary with material and manufacturing history, constant $D$ could be determined by best fitting the experimental results obtained under predetermined conditions of stress and solution temperature. According to the experimental results of SRA Zircaloy-4 cladding specimens solution-annealed at $400{ }^{\circ} \mathrm{C}$, constant $D$ was determined to be 24000 , with which the effects of applied hoop stress on the reorientation behavior under different solution temperatures are plotted in Fig. 5. The exponential relationship between the percentage of radial hydride and the applied stress was observed by other workers $[8,15]$. Eq. (10) predicts the effects of solution temperature on the reorientation behavior under a hoop stress of $160 \mathrm{MPa}$, as exemplified in Fig. 6. Besides the experimental data of the specimens solution-treated at $400{ }^{\circ} \mathrm{C}$, additional tests on the hydrided specimens annealed at $300{ }^{\circ} \mathrm{C}$ and $450{ }^{\circ} \mathrm{C}$ under the same hoop stress were made to verify the applicability of the predicted curve. It shows a good agreement between the predicted curve and experimental data at different solution temperatures. According to the results shown in Fig. 6, more than $90 \%$ of dissolved hydrides would reorient into the radial direction when specimens were heated to $450{ }^{\circ} \mathrm{C}$ for $2 \mathrm{~h}$ under a hoop stress of $160 \mathrm{MPa}$.

The results shown in Figs. 5 and 6 were calculated on the assumption that only dissolved hydrides can be reoriented. For the practical applications to fuel cladding in dry storage, the specimen (bulk) hydrogen concentration should be taken into consideration. For example, if the hydrogen concentration of the specimen was lower than its TSS at

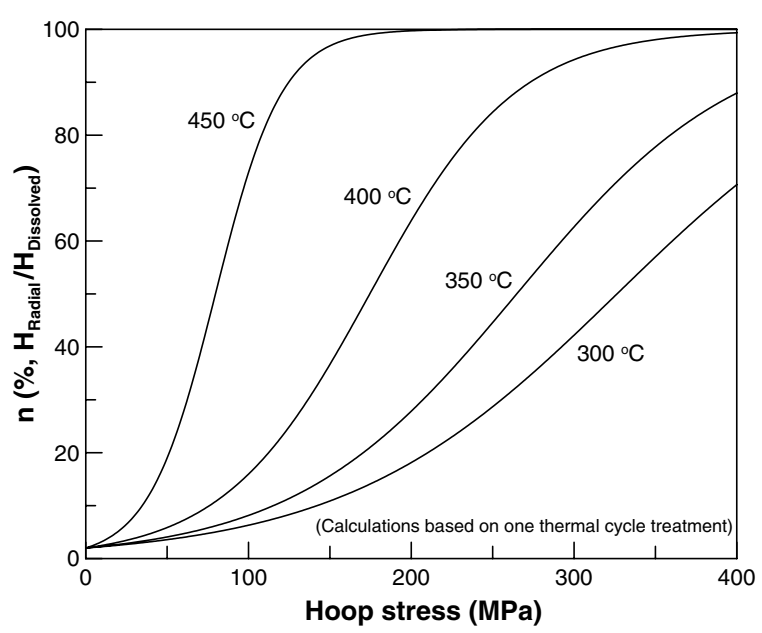

Fig. 5. Effect of hoop stress on the reorientation behavior of hydrides in SRA Zircaloy-4 tubing specimens solution-annealed at various temperatures for $2 \mathrm{~h}$.

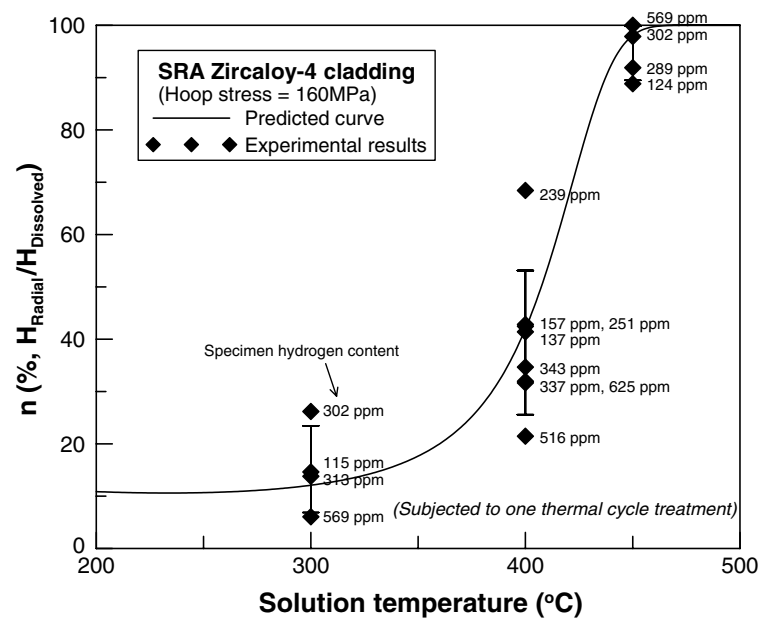

Fig. 6. Effect of solution temperature on the reorientation behavior of hydrides in SRA Zircaloy-4 tubing specimens under a constant hoop stress of $160 \mathrm{MPa}$.

the holding temperature, the precipitation of dissolved hydrides would not occur until it was further cooled. On the other hand, some hydrides would remain in the precipitate state, not dissolved, if the bulk hydrogen content higher than the TSS at the holding temperature. Plotted in Fig. 7 is the effect of specimen hydrogen content and solution temperature on the fraction of radial hydrides. The calculated percentages of radial hydrides varying with specimen hydrogen show a good agreement in trend with the experimental data for those specimens solution-treated at $300{ }^{\circ} \mathrm{C}$ and $400{ }^{\circ} \mathrm{C}$. However, the model underestimates the stress effect on the 130 and $600 \mathrm{ppm} \mathrm{H}$ specimens at $450{ }^{\circ} \mathrm{C}$ where almost all hydrides were reoriented, whether

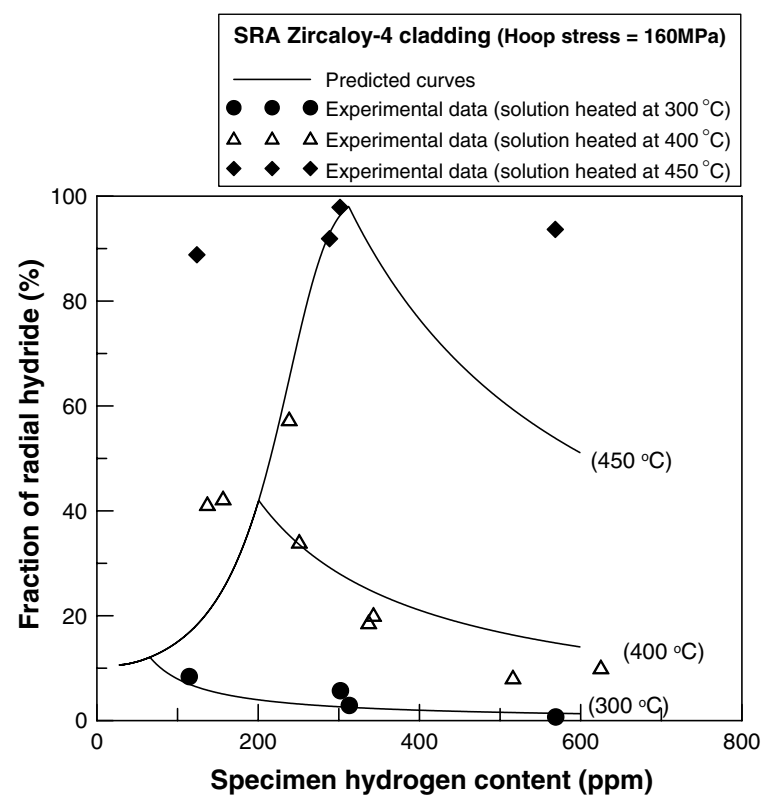

Fig. 7. Comparison between the model predictions and the experimental results on the hydride reorientation in Zircaloy-4 cladding tubes with various hydrogen concentrations subjected to one cycle of thermal treatment. 


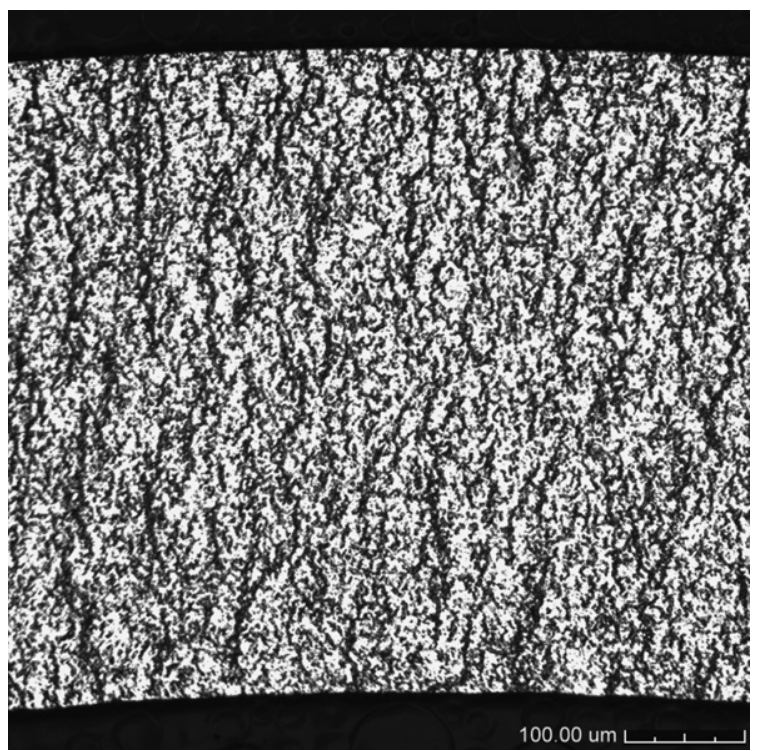

Fig. 8. Hydride morphology of Zircaloy-4 with hydrogen content of $\sim 600 \mathrm{ppm}$ subjected to solution heat treatment at $450{ }^{\circ} \mathrm{C}$ for $2 \mathrm{~h}$ under a hoop stress of $160 \mathrm{MPa}$.

hydrides are dissolved or not. Fig. 8 shows the hydride morphology of Zircaloy-4 with a hydrogen content of $\sim 600 \mathrm{ppm}$ subjected to the solution treatment at $450{ }^{\circ} \mathrm{C}$ for $2 \mathrm{~h}$ under a hoop stress of $160 \mathrm{MPa}$. It is evident that some circumferential hydrides were reoriented into radial direction; some of them became directionless hydride precipitates as well. Annealing at $450{ }^{\circ} \mathrm{C}$ under tension promoted the hydrogen atoms moving toward more stable sites by a diffusion process during the solution treatment, and therefore the stress reorientation of hydrides was enhanced. The results suggest that the diffusion of hydrogen atom could play an important role in the hydride reorientation behavior if the specimen is annealed at higher temperatures.

\subsubsection{Formation of radial hydrides}

To ensure the cladding integrity, Interim Staff Guidance-11, Revision 3 (ISG-11) is used by the US NRC staff when reviewing analyses of the potential for spent fuel reconfiguration during storage conditions [22]. It contains some limitations on the peak cladding temperature, cladding hoop stress and repeated thermal cycling. These acceptance criteria are proposed on the ground of the reduction in cladding ductility associated with the formation of radial hydrides. If the hoop stress applied on the cladding tube is lower than a critical value (threshold stress), the stress orientation of hydrides will not happen. Bai et al. [23] modeled the stress reorientation behavior at $400{ }^{\circ} \mathrm{C}$ for fully recrystallized Zircaloy- 4 and concluded that a stress of $95 \mathrm{MPa}$ should be applied to make some detectable modification of hydride orientation. The results of high-burnup Zircaloy-4 fuel cladding demonstrated that irradiation appeared not to affect the threshold stress [24]. Such a threshold stress was approximately 75-80 MPa for both non-irradiated and irradiated Zircaloy-4 fuel cladding heat treated at $400{ }^{\circ} \mathrm{C}$. Based on the data from open literature, Chung [25] showed that hydride reorientation occurred in a range of applied hoop stresses and isothermal annealing temperatures. He suggested that the threshold stress for reorientation was about $90 \mathrm{MPa}$ in a temperature range between 250 and $550^{\circ} \mathrm{C}$.

From the results in Figs. 5-7, the percentage of radial hydrides under each combination of stress and temperature was computed. Then the stress-temperature boundary curve for the occurrence of stress reorientation of hydrides was determined for each hydrogen concentration level, as plotted in Fig. 9. Here, the phenomenon of stress reorientation was defined to be observable if the fraction of radial hydrides in a specimen was higher than $5 \%$. According to the assumption given above, ' $5 \mathrm{ppm}$ ' of hydrogen precipitated in radial hydrides was already enough to define the occurrence of 'stress-reoriented' in a 100 ppm H cladding tube, whereas $25 \mathrm{ppm}$ of hydrogen in radial hydrides were needed for a $500 \mathrm{ppm} \mathrm{H}$ specimen to meet this criterion. The boundary curves therefore shift to the region of higher stress and annealing temperature as the specimen hydrogen content increases.

The horizontal lines in Fig. 9 delineate the specific temperature ranges where all hydrides in a specimen were completely dissolved. For a specimen of $100 \mathrm{ppm}$ hydrogen, all hydrides dissolved when it was heated to about $340{ }^{\circ} \mathrm{C}$. These dissolved hydrogen atoms would re-precipitate out only when specimen was cooled below $340{ }^{\circ} \mathrm{C}$ no matter how high the solution temperatures were. Accordingly, under the same applied stress, the extent of stress reorientation in the $100 \mathrm{ppm} \mathrm{H}$ specimens was not varied with the solution temperature from $340{ }^{\circ} \mathrm{C}$ and up if the

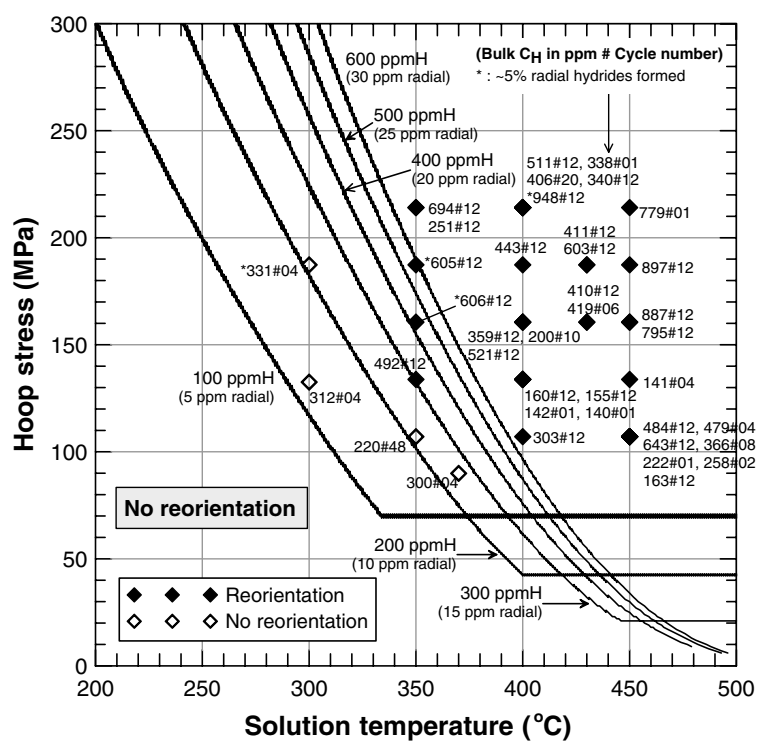

Fig. 9. Applied hoop stress for hydride reorientation as a function of isothermal solution temperature and specimen hydrogen concentration. The hydrogen concentration in parenthesis is to define the resolution of radial hydrides observable for each hydrogen level. 
diffusion effect of hydrogen atoms was neglected. In contrast to the low hydrogen specimens, the high hydrogen ones allowed the nucleation of hydrides to occur at higher temperatures. The effect of stress on hydride reorientation was more efficient at elevated temperatures (as shown in Fig. 6) and therefore it was possible to have hydrides reorientated under lower hoop stresses at higher solution temperatures. The calculated stress-temperature bounds plotted in Fig. 9 also show a good agreement with the open literature data [25] and the results of other experiments on the Zircaloy-4 cladding specimens with hydrogen concentration levels ranging from 150 to $900 \mathrm{wt}$ ppm conducted by this laboratory. In this model, the effect of stress on hydride reorientation is assumed to be most remarkable in the nucleation stage. However, more work on the effects of hydrogen diffusion and applied stress in the growth stage [26] remains to be done.

\subsection{Comparison between thermal cycling and isothermal treatment}

In addition to the effect of thermal cycling [27-29], Hong and Lee [4] and Chen et al. [30] have concluded that the formation of radial hydrides was also a time-dependent process because an increase in annealing time also raised the amount of radial hydrides in an isothermal heat treatment. In order to compare the difference between isothermal annealing and thermal cycling heat treatments, a cladding tube of $320 \mathrm{ppm} \mathrm{H}$ were solution treated at $400{ }^{\circ} \mathrm{C}$ for $24 \mathrm{~h}$ for one cycle. The hoop stress and the heat-up/cool-down rates were identical to those used in the hydride reorientation experiment described in Section 2.2 . Only $38 \%$ radial hydrides were obtained. In contrast to the isothermal treatment, nearly complete reorientation of hydrides was observed on the specimen of the same hydrogen concentration level after 12 cycles (Section 3.1). Since the accumulated intervals of solution-annealing for both cyclic and isothermal treatments were the same (i.e. $24 \mathrm{~h}$ ), it can be inferred that the effect of thermal cycling on the hydride reorientation was significant.

The enhanced effect of thermal cycling on the stress reorientation is, to a certain extent, similar to the phenomenon of hydrogen supercharging in zirconium-based material that can be achieved by repeated heating and cooling [31-33]. Supercharging was attributed to the incomplete dissolution of hydride precipitates. Owing to the difference in TSS between cooling and heating, a residual amount of hydride precipitates will remain when a hydrided specimen was reheated to the same holding temperature. Hydrogen atoms were supplied unfailingly from the cladding outer surface during a hydrogen charging process, whereas the reorientation was related to the dissolution and precipitation processes of the already existed hydrides. Even so, the reinforcement effect of thermal cycling on the hydride reorientation was possibly attributed to the incomplete dissolution of hydrides. Because the energy preference was assumed to be caused by hoop stress, the proportion of cir- cumferential hydrides dissolved could be larger than that of radial ones, when a hydrided specimen was heated under stress to the holding temperature for the first several cycles. Then an increase in the amount of radial hydrides took place after the specimen was cooled. The increment of radial hydride decreased as the thermal cycle number increased. In this study, thermal cycling treatment promoted nearly complete reorientation of hydrides in the 200-300 ppm H specimens. However, a maximum amount of only $20 \%$ radial hydrides was obtained in the $600 \mathrm{ppm} \mathrm{H}$ specimens under the same thermal cycle treatment. More work, especially from the kinetic perspective, is needed to verify the role of thermal cycling in the hydride reorientation process.

\section{Conclusions}

1. Hydrided specimens with bulk hydrogen content from 130 to $600 \mathrm{wt}$ ppm were thermally cycled in an autoclave under a constant hoop stress. The percentage of radial hydrides increased as the number of thermal cycles increased until it reached a saturated value.

2. More than $90 \%$ of hydride precipitates in the 200 $300 \mathrm{ppm} \mathrm{H}$ specimens were reoriented into the radial direction after 12 thermal cycles, but the same thermal cycle treatment induced only $20 \%$ radial hydrides in the $600 \mathrm{ppm} \mathrm{H}$ specimens.

3. The effect of thermal cycling on the hydride reorientation was more significant than that of isothermal treatment.

4. The diffusion of hydrogen atoms could play an important role in the hydride reorientation process if a specimen was solution-treated at $450^{\circ} \mathrm{C}$.

5. A thermodynamics model for evaluating the susceptibility to radial hydride formation in the SRA Zircaloy-4 cladding was proposed. According to the model, the bounds of stress and temperature to stress reorientation of hydride precipitates were developed. The threshold stress for hydrides to reorientation was a function of solution temperature and specimen hydrogen concentration.

\section{Acknowledgements}

This research was funded by both the National Science Council, Taiwan, under Contract No. NSC94-3111-042A002-Y20, and the Institute of Nuclear Energy Research, Taiwan.

\section{References}

[1] R.P. Marshall, M.R. Louthan Jr., Trans. ASM 56 (1963) 693.

[2] M.R. Louthan Jr., R.P. Marshall, J. Nucl. Mater. 9 (2) (1963) 170.

[3] R.N. Singh, R. Kishore, S.S. Sinha, T.K. Sinha, B.P. Kashyap, J. Nucl. Mater. 325 (2004) 26.

[4] S.I. Hong, K.W. Lee, J. Nucl. Mater. 340 (2005) 203.

[5] R.P. Marshall, J. Nucl. Mater. 24 (1967) 34.

[6] R.P. Marshall, J. Nucl. Mater. 24 (1967) 49.

[7] J.J. Kearns, C.R. Woods, J. Nucl. Mater. 20 (1966) 241.

[8] M. Leger, A. Donner, Can. Metall. Q. 24 (3) (1985) 235. 
[9] W. Goll, H. Spilker, E.H. Toscano, J. Nucl. Mater. 289 (2001) 247.

[10] J.P. Foster, M. Dahlback, A. Donaldson, T. Gilmour, R. Kesterson, ICAPP Embedded Topical Meeting Hollywood, Florida, June. 9-13, 2002.

[11] G. Domizzi, G. Vigna, S. Bermúdez, J. Ovejero-García, J. Nucl. Mater. 275 (1999) 255.

[12] S. Shimada, E. Etoh, H. Hayashi, Y. Tukuta, J. Nucl. Mater. 327 (2004) 97.

[13] H.C. Chu, S.K. Wu, K.F. Chien, R.C. Kuo, J. Nucl. Mater. 326 (2007) 93.

[14] J.J. Kearns, J. Nucl. Mater. 22 (1967) 292.

[15] D. Hardie, M.W. Shanahan, J. Nucl. Mater. 55 (1975) 1.

[16] D.A. Porter, K.E. Easterling, Phase Transformations in Metals and Alloys, 2nd Ed., Nelson Thornes Ltd., UK, 2001.

[17] V. Perovic, G.C. Weatherly, C.J. Simpson, Acta Metall. 31 (1983) 1381.

[18] C.E. Ells, J. Nucl. Mater. 35 (1970) 306.

[19] M.P. Puls, AECL-8381, Atomic Energy of Canada Limited, Whiteshell Nuclear Research Establishment, 1984.

[20] M.P. Puls, Acta Metall. 29 (1981) 1961.

[21] M.P. Puls, Acta Metall. 32 (8) (1984) 1259.
[22] E.W. Brach, Interim Staff Guidance-11, Revision 3, US NRC, Spent Fuel Project Office, 2003.

[23] J.B. Bai, N. Ji, D. Gilbon, C. Prioul, D. Francois, Metall. Mater. Trans. A 25A (1994) 1199.

[24] R.S. Duam, S. Majumdar, Y. Liu and M.C. Billone, Water Reactor Fuel Performance Meeting, Kyoto, Japan, October 2-6, 2005.

[25] H.M. Chung, in: Proceedings of the International Meeting on LWR Fuel Performance, Orlando, FL, September 19-22, 2004.

[26] Y. Mishima, S. Ishino, H. Kawanishi, Proceeding of Congress International 'L'Hydrohene dans les Metaux' 2 (1972) 489.

[27] Y. Mishima, T. Okubo, Can. Metall. Q 11 (1) (1972) 157.

[28] H. Maki, J. Nucl. Sci. Technol. 10 (8) (1973) 470.

[29] B.F. Kammenzind, B.M. Berquist, R. Bajaj, P.H. Kreyns, D.G. Franklin, in: G.P. Sabol, G.D. Moan (Eds.), Twelfth International Symposium, ASTM STP, vol. 1354, American Society for Testing and Materials, 2000, p. 196.

[30] J.H. Chen, N.K. Sungyu, C.C. Perng, W.J. Liaw, R.C. Kuo, INERT2562, Institute of Energy Research, 1999.

[31] R. Westerman, J. Nucl. Mater. 18 (1966) 31.

[32] D.G. Westake, S.T. Ockers, J. Nucl. Mater. 37 (1970) 236.

[33] Y. Mishima, S. Ishino, S. Nakajima, J. Nucl. Mater. 27 (1968) 335. 